\title{
Anti-TNF therapy in Jordan: a focus on severe infections and tuberculosis
}

\author{
This article was published in the following Dove Press journal: \\ Biologics: Targets and Therapy \\ 22 April 2014 \\ Number of times this article has been viewed
}

\author{
Khaldoon M Alawneh' \\ Mahmoud H Ayesh' \\ Basheer Y Khassawneh' \\ Salwa Shihadeh Saadeh' \\ Mahmoud Smadi² \\ Khaldoun Bashaireh ${ }^{3}$ \\ 'Department of Medicine, College of \\ Medicine, King Abdullah University \\ Hospital, ${ }^{2}$ College of Science, \\ ${ }^{3}$ Department of Special Surgery, \\ College of Medicine, King Abdullah \\ University Hospital, Jordan University \\ of Science and Technology, Irbid, \\ Jordan
}

Background: A high rate of infection has been reported in patients receiving treatment with anti-tumor necrosis factor (anti-TNF). This study describes the rate of and risk factors for serious infections in patients receiving anti-TNF agents in Jordan.

Methods: This retrospective observational study was conducted at a large tertiary referral center in the north of Jordan. Between January 2006 and January 2012, 199 patients who received an anti-TNF agent (infliximab, adalimumab, or etanercept) were included. Patients received the anti-TNF treatment for rheumatoid arthritis, ankylosing spondylitis, inflammatory bowel disease, or other conditions. A serious infection was defined as any bacterial, viral, or fungal infection that required hospitalization, administration of appropriate intravenous antimicrobial therapy, and temporary withholding of anti-TNF treatment.

Results: The mean duration of anti-TNF treatment was 26.2 months. Steroids were used in $29.1 \%$ of patients, while $54.8 \%$ were given additional immunosuppressant therapy (methotrexate or azathioprine). Only one anti-TNF agent was given in $70.4 \%$ of patients, while $29.6 \%$ received different anti-TNF agents for the duration of treatment. Serious infections were documented in 39 patients (19.6\%), including respiratory tract infections (41\%), urinary tract infections $(30.8 \%)$, and skin infections (20.5\%), and extrapulmonary tuberculosis in three patients (7.7\%). Exposure to more than one anti-TNF agent was the only factor associated with a significant increase in the rate of infection (relative risk 1.9, 95\% confidence interval 1.06-4.0, $P=0.03$ ).

Conclusion: Serious infections, including tuberculosis, were a common problem in patients receiving anti-TNF agents, and exposure to more than one anti-TNF agent increased the risk of serious infection.

Keywords: anti-tumor necrosis factor therapy, biologics, developing world, extra-pulmonary tuberculosis, immune mediated diseases

\section{Introduction}

Since its introduction in 1998, anti-tumor necrosis factor (anti-TNF) has markedly changed the treatment and outcome of many inflammatory diseases. ${ }^{1}$ The efficacy and safety of these agents has been reviewed extensively in the literature. ${ }^{2-4}$ Early randomized clinical trials showed an increased risk of serious infection that was confirmed to be even higher in later daily practice studies. ${ }^{5,6}$ However, these studies have had inconsistent results with regard to the safety profile. Some reports have shown an increase in the overall serious infection rate, ${ }^{7,8}$ while others reported no significant increase in serious infections. ${ }^{9-11}$ The increased risk of developing tuberculosis has been of special concern due to the important biological role of TNF in formation of granuloma and containment of the disease. ${ }^{12}$ The increased rate of tuberculosis has been attributed in some reports to be due to inadequate screening for latent tuberculosis
Correspondence: Khaldoon M Alawneh Department of Medicine, College of Medicine, King Abdullah University Hospital, Jordan University of Science and Technology, PO box 3030 , Irbid 221 I0, Jordan Email kma1234@msn.com 
before initiation of treatment, ${ }^{13,14}$ while other reports found a consistent increase in new cases despite adequate preventive measures. ${ }^{15,16}$

Most of the data regarding the safety of anti-TNF agents with regard to infection have been reported from western populations that are believed to have a lower background rate of infections in general and of tuberculosis in particular as compared with developing countries. ${ }^{17-19}$ Jordan is a developing country located in the Middle East with an estimated population of 6 million. The three anti-TNF agents currently licensed for use in patients with immunemediated diseases in Jordan are infliximab, etanercept, and adalimumab. These agents have been shown to be effective in treating immune-mediated diseases. ${ }^{20}$

This study describes a large tertiary center experience in the north of Jordan regarding the development of serious infections, including tuberculosis, in association with use of these three anti-TNF agents.

\section{Materials and methods}

This retrospective observational study was conducted at King Abdullah University Hospital, Irbid, Jordan. King Abdullah University Hospital is a large referral center for the north of Jordan. All patients who received one month or more of anti-TNF treatment from January 2006 to January 2012 were identified through the hospital electronic pharmacy records.

Collected data included patient demographics, underlying disease for which the anti-TNF was prescribed, and the presence of any comorbidity like diabetes mellitus, hypertension, renal failure, bronchial asthma, or malignancy. Also, the type of anti-TNF agent used, duration of anti-TNF treatment, and concomitant immunosuppressant medications used (prednisolone $\geq 5 \mathrm{mg}$ per day, methotrexate, or azathioprine) were collected. A serious infection was defined as any bacterial, viral, or fungal infection that required hospitalization, administration of appropriate intravenous antimicrobial therapy, and temporary withholding of anti-TNF treatment.

All patients were screened for tuberculosis by standard tuberculin skin testing before initiation of anti-TNF treatment and yearly for the duration of therapy. Tuberculin skin testing $\geq 5 \mathrm{~mm}$ was considered positive. Patients with a positive tuberculin skin test and a normal chest radiograph received isoniazid for 9 months. Duration of treatment was defined as the time from initiation of anti-TNF therapy until discontinuation of data collection. Data were collected from the hospital medical records and by directly contacting patients.

Both descriptive and inferential techniques were used in the statistical analysis. In the descriptive statistics, means and standard deviations of age in years at initiation of anti-TNF and duration of treatment with an anti-TNF were computed. Frequencies and percentages were used to describe categorical patient characteristics. Cross-tabulation summaries of agent versus infection and agent versus patient characteristics are given. In the inferential statistics, relative risk and its confidence interval for patients who were exposed to more than one anti-TNF associated with infection were computed. The formulae for computing the relative risk and confidence interval are given in the Results section. Test of association using Pearson's chi-square test of independence was also used in the analysis. Statistical Package for Social Sciences version 17 software (SPSS Inc., Chicago, IL, USA) was used to perform all statistical analyses. The study was approved by the institutional review board of Jordan University of Science and Technology and King Abdullah University Hospital in the north of Jordan.

\section{Results}

In total, 199 patients were included in the study. The mean age at initiation of anti-TNF therapy was 39.2 (6-75) years, and $50.8 \%$ of patients were males.

Rheumatoid arthritis was the underlying disease in 85 patients (42.7\%), ankylosing spondylitis in 47 (23.6\%), inflammatory bowel disease in $28(14.1 \%)$, psoriasis and psoriatic arthritis in $21(10.6 \%)$, juvenile idiopathic arthritis in eight (4\%), Behçet's disease in eight (4\%), and idiopathic uveitis in two (1\%). The mean duration of treatment with anti-TNF agents was 26.2 (range, 1-91) months. Steroids were used in 54 patients $(27.1 \%)$. The mean dose of oral prednisolone was 8.1 (range, 5-40) mg/day. Other immunosuppressants (methotrexate or azathioprine) were used in 109 patients $(54.8 \%)$. Only a single anti-TNF agent was used in 140 patients $(70.4 \%)$ throughout the duration of treatment, while 59 patients $(29.6 \%)$ switched to another agent during the treatment period. A summary of patient characteristics according to agent used is provided in Table 1.

Serious infections were documented in 36 patients (18.1\%). Respiratory tract infections were the most commonly encountered, with a total of 16 episodes (41\%), followed by urinary tract infections (12 episodes, 30.8\%) and skin infections (eight episodes, 20.5\%, Table 2). Three patients $(7.7 \%)$ developed active extrapulmonary tuberculosis despite a negative tuberculin skin test prior to initiation of anti-TNF therapy (Table 3).

Of the 36 patients who had serious infection, seven (19.4\%) required admission to intensive care for septic shock and hypoxia. One patient with rheumatoid arthritis on 
Table I Patient characteristics according to anti-TNF agent used

\begin{tabular}{llllllll}
\hline $\begin{array}{l}\text { Type of } \\
\text { anti-TNF }\end{array}$ & Patients (n) & $\begin{array}{l}\text { Age, years } \\
(\text { mean } \pm \text { SD) }\end{array}$ & $\begin{array}{l}\text { Duration of } \\
\text { treatment, months } \\
(\text { mean } \pm \text { SD) }\end{array}$ & $\begin{array}{l}\text { Patients on } \\
\text { steroids }^{\mathbf{a}}(\mathbf{n})\end{array}$ & $\begin{array}{l}\text { Oral steroid } \\
\text { dose (mg/day) } \\
(\mathbf{m e a n} \pm \text { SD) }\end{array}$ & $\begin{array}{l}\text { Nonbiological } \\
\text { immunosuppressants }\end{array}$ & $\begin{array}{l}\text { Serious } \\
\text { infection }\end{array}$ \\
\hline All & 199 & $39.2 \pm 14.5$ & $26.2 \pm 17.4$ & $54(27.1 \%)$ & $8.1 \pm 6.4$ & $109(54.8 \%)$ & $36(18.1 \%)$ \\
Infliximab & $53(26.7 \%)$ & $38.2 \pm 14.2$ & $22.7 \pm 18.8$ & $15(27.8 \%)$ & $6.8 \pm 2.4$ & $25(47.2 \%)$ & $11(20.8 \%)$ \\
Adalimumab & $61(30.7 \%)$ & $41.6 \pm 13.4$ & $19.1 \pm 9.9$ & $18(33.3 \%)$ & $8.6 \pm 7.2$ & $43(70.5 \%)$ & $7(11.5 \%)$ \\
Etanercept & $26(13.1 \%)$ & $42 \pm 13.2$ & $25.5 \pm 15.3$ & $8(14.8 \%)$ & $6.6 \pm 2.3$ & $14(53.8 \%)$ & $2(7.8 \%)$ \\
Multiple agents & $59(29.6 \%)$ & $36.4 \pm 13.4$ & $36.9 \pm 18.2$ & $13(24.1 \%)$ & $9.6 \pm 9.5$ & $27(45.7 \%)$ & $16(27.1 \%)$ \\
\hline
\end{tabular}

Notes: aSteroids, oral prednisolone; 'bexposure to more than one anti-TNF agent.

Abbreviations: TNF, tumor necrosis factor; SD, standard deviation.

adalimumab required mechanical ventilation post coronary artery bypass surgery and eventually died from pneumonia and septic shock. Two patients were receiving infliximab for Crohn's disease and died from septic shock.

Patients who were exposed to more than one anti-TNF agent had a higher risk of serious infection than those who received a single anti-TNF, ie, $16 / 59(27.1 \%)$ versus $20 / 140$ $(14.3 \%)$, respectively, with a relative risk of $1.9(95 \%$ confidence interval 1.06-4.0, $P=0.03)$. This association remained significant after adjusting for potential confounding factors such as age, sex, steroid use, primary diagnosis, comorbidities, and use of another immunosuppressant.

\section{Discussion}

This is the first study from Jordan to report the risk of infection in patients with immune-mediated diseases requiring treatment with anti-TNF agents. The rate of infection, including tuberculosis, was much higher than what has been reported in western countries. Anti-TNF agent switchers had a higher risk of infection.

Anti-TNF agents have been shown to be effective in treating immune-mediated diseases. ${ }^{21}$ One proposed mechanism is neutralization of soluble TNF or blocking TNF receptors from binding to their ligands. A complement-mediated effect may be as important as the anti-TNF effect on intracellular signaling, resulting in apoptosis and suppression of cytokine production. ${ }^{22}$ Studies have suggested that TNF signaling in tuberculosis is required for macrophage survival, and lack of this signal causes increased macrophage death and necrosis, leading to disease reactivation. This loss of TNF signaling confers a bacterial growth advantage, both within the macrophage and in the extracellular space after death of the macrophage. ${ }^{23}$ It is generally known that patients with chronic inflammatory disease have an increased risk of infection for several disease-related reasons. ${ }^{24,25}$

In our study, almost one in five patients receiving anti-TNF treatment developed a serious infection. Exposure to more than one anti-TNF agent during therapy doubles the risk of developing a serious infection. How much of this percentage is excess risk attributable to anti-TNF therapy is not known due to lack of a control group. It is difficult to assemble an adequate cohort of controls because patients requiring anti-TNF treatment usually have more severe disease which, in itself, leads to a higher background risk of infection regardless of the treatment received. ${ }^{26,27} \mathrm{We}$ attempted to identify the factors associated with development of infection in exposed patients. The only variable that appeared to have a significant association with development of a serious infection was exposure to more than one antiTNF agent.

To the authors' knowledge, this study is the first to report the risk of infection in patients receiving anti-TNF treatment in Jordan. There are no published data from the Middle East that describe the rate of infection in patients taking anti-TNF agents

Table 2 Patient characteristics according to type of infection

\begin{tabular}{|c|c|c|c|c|}
\hline & $\begin{array}{l}\text { Extrapulmonary } \\
\text { tuberculosis }\end{array}$ & $\begin{array}{l}\text { Respiratory } \\
\text { infections }\end{array}$ & $\begin{array}{l}\text { Urinary tract } \\
\text { infections }\end{array}$ & $\begin{array}{l}\text { Skin and soft } \\
\text { tissue infections }\end{array}$ \\
\hline Patients (n) & 3 & 16 & 12 & 8 \\
\hline Mean age (years) & 41.0 & 35.2 & 29.8 & 38.1 \\
\hline $\begin{array}{l}\text { Mean duration of anti-TNF } \\
\text { therapy (months) }\end{array}$ & 29.7 & 34.7 & 25.1 & 38.3 \\
\hline Oral prednisolone use (n) & $2(66.7 \%)$ & $7(43.8 \%)$ & $4(33.3 \%)$ & $3(37.5 \%)$ \\
\hline Other immunosuppressants (n) & I (33.3\%) & $10(62.5 \%)$ & $9(75 \%)$ & $6(75 \%)$ \\
\hline
\end{tabular}

Abbreviation: TNF, tumor necrosis factor. 
Table 3 Characteristics of patients who developed active tuberculosis

\begin{tabular}{|c|c|c|c|c|c|c|c|c|}
\hline & $\begin{array}{l}\text { Age, } \\
\text { (years) }\end{array}$ & Sex & Diagnosis & $\begin{array}{l}\text { Site of } \\
\text { infection }\end{array}$ & $\begin{array}{l}\text { Anti-TNF } \\
\text { agent }\end{array}$ & $\begin{array}{l}\text { Months of anti- } \\
\text { TNF treatment }\end{array}$ & Steroids & $\begin{array}{l}\text { Other } \\
\text { immunosuppressants }\end{array}$ \\
\hline Patient I & 42 & Female & RA & Peritoneal & Adalimumab & 33 & Yes & Methotrexate \\
\hline Patient 2 & 28 & Female & RA & Peritoneal & $\begin{array}{l}\text { Adalimumab + } \\
\text { etanercept }\end{array}$ & 50 & No & None \\
\hline Patient 3 & 53 & Male & IBD & Miliary & Infliximab & 6 & Yes & None \\
\hline
\end{tabular}

Abbreviations: RA, rheumatoid arthritis; IBD, inflammatory bowel disease; TNF, tumor necrosis factor.

for immune-mediated disease. ${ }^{28}$ Earlier data from Switzerland reported a rate of serious infection of $18.3 \%$ in patients with rheumatoid arthritis treated with anti-TNF agents, which is similar to what we found. ${ }^{29}$ Lane et al, in a large retrospective study of veterans treated with anti-TNF agents, reported that $7 \%$ of their patients had at least one admission for a serious infection. ${ }^{30}$ They also reported a higher risk of hospitalization with the use of infliximab compared with etanercept and a higher risk for hospitalization in patients taking prednisolone. In that study, infliximab was associated with a higher rate of infection compared with etanercept and adalimumab, which is in line with published international reports, ${ }^{31}$ although the difference was not statistically significant. The most common encountered infections were those of the respiratory tract (41\%), which is consistent with several earlier studies in patients treated with anti-TNF agents. ${ }^{32,33}$ Similarly, use of steroids or other immunosuppressants has been associated with a higher rate of infection, but statistical significance could not be demonstrated likely due to the sample size. ${ }^{34}$

The only factor that was associated with a statistically significant increase in rate of infection was switching between multiple anti-TNF agents. In a large population-based study, Curtis et al reported a similar higher infection rate in anti-TNF switchers (seven per 100 patient-years) as compared with firsttime users (4.6 per 100 patient-years). ${ }^{35}$ Askling et al reported a similar finding, with a relative risk of infection of 2.1 for second anti-TNF users versus 1.43 for first-time users. ${ }^{36}$ Kumar et al reported a rate of reactivation of latent tuberculosis as high as $10.6 \%$ in Indian patients treated with infliximab. ${ }^{37}$ This comes from a population with a higher background prevalence of tuberculosis compared with the low prevalence in Jordan. In the USA, Wallis et al reported tuberculosis occurring in 144 and 35 per 100,000 of infliximab-treated and etanercept-treated patients, respectively. ${ }^{38}$ This is similar to a report by Dixon et al in the UK. ${ }^{39}$ In their study, $1.5 \%$ of treated patients developed extrapulmonary tuberculosis. This rate is lower than what has been reported in India but much higher than in the USA. This can be explained by the lower rate of tuberculosis in Jordan as reported by the World Health Organization (six per 100,000 population). ${ }^{40}$
We reported three cases of extrapulmonary tuberculosis in patients who were receiving anti-TNF therapy despite negative pretreatment screening with a tuberculin skin test. Interferon gamma release assays are thought to be superior to tuberculin skin testing in areas where Bacillus CalmetteGuerin (BCG) vaccination exposure is prevalent, ${ }^{41}$ such as in Jordan where BCG is part of the national vaccination program. In a recent meta-analysis, tuberculin skin test positivity was influenced by BCG vaccination whereas interferon gamma release assays were not affected, and positivity of the interferon gamma release assay was associated with exposure to patients with active tuberculosis. ${ }^{42,43}$

Interferon gamma release assays are not widely available in Jordan, so our patients are only routinely screened by tuberculin skin testing. All three of the detected tuberculosis cases were extrapulmonary, consistent with previous reports that repeatedly estimated extrapulmonary tuberculosis to constitute more than $50 \%$ of cases of tuberculosis in patients treated with anti-TNF. ${ }^{44}$ Two of the detected cases were peritoneal tuberculosis and the third was miliary tuberculosis. All three patients who developed tuberculosis were treated successfully with anti-tuberculous medications, and went back on a nonbiological immunosuppressant for the primary disease.

The lack of published local or regional data regarding infection in patients receiving anti-TNF therapy for immunemediated diseases limited our ability to validate the present findings. The small sample size was a limiting factor in our study, because statistical significance could not be attained for measured frequencies. However, the similarities between the findings of this study and prior international reports do increase the reliability of our measured outcomes.

Microbiology data describing causative organisms and possibly the pattern of resistance would have enriched the results of this study. However, being a retrospective study, these data were not collected.

\section{Conclusion}

Our study is the first from Jordan to report the risk of infection in patients with immune-mediated diseases requiring treatment with anti-TNF agents. Physicians treating 
immune-mediated diseases should be aware of the high risk of infection and in particular the risk of extrapulmonary tuberculosis in this patient population. In the future, a national registry should be established to help in documenting and improving outcomes of treatment for immune-mediated diseases. $^{45}$

\section{Disclosure}

The authors report no conflicts of interest in this work.

\section{References}

1. Geiler J, Buch M, McDermott MF. Anti-TNF treatment in rheumatoid arthritis. Curr Pharm Des. 2011;17(29):3141-3154.

2. Lin J, Ziring D, Desai S, et al. TNFalpha blockade in human diseases: an overview of efficacy and safety. Clin Immunol. 2008;126(1):13-30.

3. Ali T, Kaitha S, Mahmood S, Ftesi A, Stone J, Bronze MS. Clinical use of anti-TNF therapy and increased risk of infections. Drug Healthc Patient Saf. 2013;5:79-99.

4. Kievit W, Fransen J, Oerlemans A, et al. The efficacy of anti-TNF in rheumatoid arthritis, a comparison between randomised controlled trials and clinical practice. Ann Rheum Dis. 2007;66(11):1473-1478.

5. Bongartz T, Sutton AJ, Sweeting MJ, Buchan I, Matteson EL, Montori V. Anti-TNF antibody therapy in rheumatoid arthritis and the risk of serious infections and malignancies: systematic review and metaanalysis of rare harmful effects in randomized controlled trials. JAMA. 2006;295(19):2275-2285.

6. Salliot C, Gossec L, Ruyssen-Witrand A, et al. Infections during tumour necrosis factor-alpha blocker therapy for rheumatic diseases in daily practice: a systematic retrospective study of 709 patients. Rheumatology (Oxford). 2007;46(2):327-334.

7. Komano Y, Tanaka M, Nanki T, et al. Incidence and risk factors for serious infection in patients with rheumatoid arthritis treated with tumor necrosis factor inhibitors: a report from the Registry of Japanese Rheumatoid Arthritis Patients for Longterm Safety. J Rheumatol. 2011;38(7):1258-1264.

8. Galloway JB, Mercer LK, Moseley A, et al. Risk of skin and soft tissue infections (including shingles) in patients exposed to anti-tumour necrosis factor therapy: results from the British Society for Rheumatology Biologics Register. Ann Rheum Dis. 2013;72(2):229-234.

9. Leombruno JP, Einarson TR, Keystone EC. The safety of anti-tumour necrosis factor treatments in rheumatoid arthritis: meta and exposureadjusted pooled analyses of serious adverse events. Ann Rheum Dis. 2009;68(7):1136-1145.

10. Peyrin-Biroulet L, Deltenre P, De Suray N, Branche J, Sandborn WJ, Colombel JF. Efficacy and safety of tumor necrosis factor antagonists in Crohn's disease: meta-analysis of placebo-controlled trials. Clin Gastroenterol Hepatol. 2008;6(6):644-653.

11. Fouque-Aubert A, Jette-Paulin L, Combescure C, Basch A, Tebib J, Gossec L. Serious infections in patients with ankylosing spondylitis with and without TNF blockers: a systematic review and meta-analysis of randomised placebo-controlled trials. Ann Rheum Dis. 2010;69(10): 1756-1761.

12. Wong M, Ziring D, Korin Y, et al. TNFalpha blockade in human diseases: mechanisms and future directions. Clin Immunol. 2008; 126(2):121-136.

13. Gomez-Reino JJ, Carmona L, Angel Descalzo M. Risk of tuberculosis in patients treated with tumor necrosis factor antagonists due to incomplete prevention of reactivation of latent infection. Arthritis Rheum. 2007;57(5):756-761.

14. Gomez-Reino JJ, Carmona L, Valverde VR, Mola EM, Montero MD. Treatment of rheumatoid arthritis with tumor necrosis factor inhibitors may predispose to significant increase in tuberculosis risk: a multicenter active-surveillance report. Arthritis Rheum. 2003;48(8):2122-2127.
15. Jauregui-Amezaga A, Turon F, Ordas I, et al. Risk of developing tuberculosis under anti-TNF treatment despite latent infection screening. J Crohns Colitis. 2013;7(3):208-212.

16. Winthrop KL, Baxter R, Liu L, et al. Mycobacterial diseases and antitumour necrosis factor therapy in USA. Ann Rheum Dis. 2013;72(1): $37-42$.

17. Zar HJ, Madhi SA, Aston SJ, Gordon SB. Pneumonia in low and middle income countries: progress and challenges. Thorax. 2013;68(11): $1052-1056$.

18. Murray CJ, Styblo K, Rouillon A. Tuberculosis in developing countries: burden, intervention and cost. Bull Int Union Tuberc Lung Dis. 1990;65(1):6-24.

19. Pittet D, Allegranzi B, Storr J, et al. Infection control as a major World Health Organization priority for developing countries. $J$ Hosp Infect. 2008;68(4):285-292.

20. Kim SY, Servi A, Polinski JM, et al. Validation of rheumatoid arthritis diagnoses in health care utilization data. Arthritis Res Ther 2011;13(1):R32.

21. Palladino MA, Bahjat FR, Theodorakis EA, Moldawer LL. Anti-TNF- $\alpha$ therapies: the next generation. Nat Rev Drug Discov. 2003;2(9):736-746.

22. Daniel T, Klareskog L, Sasso EH, Salfeld JG, Tak PP. Tumor necrosis factor antagonist mechanisms of action: a comprehensive review. Pharmacol Ther. 2008;117(2):244-279.

23. Clay H, Volkman HE, Ramakrishnan L. Tumor necrosis factor signaling mediates resistance to mycobacteria by inhibiting bacterial growth and macrophage death. Immunity. 2008;29(2):283-294.

24. Doran MF, Crowson CS, Pond GR, O'Fallon WM, Gabriel SE. Frequency of infection in patients with rheumatoid arthritis compared with controls: a population-based study. Arthritis Rheum. 2002;46(9): 2287-2293.

25. Johnston SS, Turpcu A, Shi N, Fowler R, Chu BC, Alexander K. Risk of infections in rheumatoid arthritis patients switching from anti-TNF agents to rituximab, abatacept, or another anti-TNF agent, a retrospective administrative claims analysis. Semin Arthritis Rheum. 2013;43(1):39-47.

26. Galloway JB, Hyrich KL, Mercer LK, et al. Anti-TNF therapy is associated with an increased risk of serious infections in patients with rheumatoid arthritis especially in the first 6 months of treatment: updated results from the British Society for Rheumatology Biologics Register with special emphasis on risks in the elderly. Rheumatology (Oxford). 2011;50(1):124-131.

27. Van Dartel SA, Fransen J, Kievit W, et al. Predictors for the 5-year risk of serious infections in patients with rheumatoid arthritis treated with anti-tumour necrosis factor therapy: a cohort study in the Dutch Rheumatoid Arthritis Monitoring (DREAM) registry. Rheumatology. 2013;52(6):1052-1057.

28. Hammoudeh M, Alarfaj A, Chen DY, Djoudi H, Youseif E, Zhu J. Safety of tumor necrosis factor inhibitors use for rheumatoid arthritis and ankylosing spondylitis in Africa, the Middle East, and Asia: focus on severe infections and tuberculosis. Clin Rheumatol. 2013;32(3): 293-300.

29. Kroesen S, Widmer AF, Tyndall A, Hasler P. Serious bacterial infections in patients with rheumatoid arthritis under anti-TNF-alpha therapy. Rheumatology (Oxford). 2003;42(5):617-621.

30. Lane MA, McDonald JR, Zeringue AL, et al. TNF-alpha antagonist use and risk of hospitalization for infection in a national cohort of veterans with rheumatoid arthritis. Medicine (Baltimore). 2011;90(2): 139-145.

31. Toh S, Li L, Harrold LR, et al. Comparative safety of infliximab and etanercept on the risk of serious infections: does the association vary by patient characteristics? Pharmacoepidemiol Drug Saf. 2012;21(5): 524-534.

32. Grijalva CG, Chen L, Delzell E, et al. Initiation of tumor necrosis factor-alpha antagonists and the risk of hospitalization for infection in patients with autoimmune diseases. JAMA. 2011;306(21): 2331-2339. 
33. Curtis JR, Xi J, Patkar N, Xie A, Saag KG, Martin C. Drug-specific and time-dependent risks of bacterial infection among patients with rheumatoid arthritis who were exposed to tumor necrosis factor alpha antagonists. Arthritis Rheum. 2007;56(12):4226-4227.

34. Grijalva CG, Kaltenbach L, Arbogast PG, Mitchel EF Jr, Griffin MR. Initiation of rheumatoid arthritis treatments and the risk of serious infections. Rheumatology (Oxford). 2010;49(1):82-90.

35. Curtis JR, Xie F, Chen L, et al. The comparative risk of serious infections among rheumatoid arthritis patients starting or switching biological agents. Ann Rheum Dis. 2011;70(8):1401-1406.

36. Askling J, Fored CM, Brandt L, et al. Time-dependent increase in risk of hospitalisation with infection among Swedish RA patients treated with TNF antagonists. Ann Rheum Dis. 2007;66(10):1339-1344.

37. Kumar A. Experience with anti-tumor necrosis factor- $\alpha$ therapy in India. APLAR Journal of Rheumatology. 2006;9(2):136-141.

38. Wallis R, Broder M, Wong J, Hanson M, Beenhouwer D. Granulomatous infectious diseases associated with tumor necrosis factor antagonists. Clin Infect Dis. 2004;38(9):1261-1265.

39. Dixon WG, Hyrich KL, Watson KD, et al. Drug-specific risk of tuberculosis in patients with rheumatoid arthritis treated with anti-TNF therapy: results from the British Society for Rheumatology Biologics Register (BSRBR). Ann Rheum Dis. 2010;69(3):522-528.
40. Public Health Agency of Canada. International tuberculosis incidence rates, 2011. Available from: http://www.phac-aspc.gc.ca/tbpc-latb/ itir-eng.php. Accessed February 25, 2014.

41. Sellam J, Hamdi H, Roy C, et al. Comparison of in vitro-specific blood tests with tuberculin skin test for diagnosis of latent tuberculosis before anti-TNF therapy. Ann Rheum Dis. 2007;66(12):1610-1615.

42. Diel RD, Goletti G, Ferrara G, et al. Interferon- $\gamma$ release assays for the diagnosis of latent Mycobacterium tuberculosis infection: a systematic review and meta-analysis. Eur Respir J. 2011;3(1):88-99.

43. Sester M, Sotgiu G, Lange C, et al. Interferon- $\gamma$ release assays for the diagnosis of active tuberculosis: a systematic review and meta-analysis. Eur Respir J. 2011;37(1):100-111.

44. Keane J, Gershon S, Wise RP, et al. Tuberculosis associated with infliximab, a tumor necrosis factor alpha-neutralizing agent. $N$ Engl J Med. 2001;345(15):1099-1104.

45. Hajjaj-Hassouni N, Al-Badi M, Al-Emadi S, et al. The practical value of biologics registries in Africa and Middle East: challenges and opportunities. Clin Rheum. 2012;31(3):407-416.
Biologics: Targets \& Therapy

\section{Publish your work in this journal}

Biologics: Targets \& Therapy is an international, peer-reviewed journal focusing on the patho-physiological rationale for and clinical application of Biologic agents in the management of autoimmune diseases, cancers or other pathologies where a molecular target can be identified. This journal is indexed on PubMed Central, CAS, EMBase, Scopus

\section{Dovepress}

and the Elsevier Bibliographic databases. The manuscript management system is completely online and includes a very quick and fair peerreview system, which is all easy to use. Visit http://www.dovepress com/testimonials.php to read real quotes from published authors. 